\title{
New Polyurethanes with a polyurea matrix
}

\author{
Vladimir Peshkov, Gerhard Behrendt, Rozeta Evtimova, Michael Herzog
}

\section{Zusammenfassung}

Basierend auf einem bereits veröffentlichten Syntheseweg (Peshkov 2011) für nanoskalige Harnstoff Dispersions Polyole (PHD) wurde ein neuer Typ von Polyurethanen mit einer Polyharnstoff Matrix entwickelt. Durch Umsetzung der PHD's mit Di- bzw. Polyisocyanaten wurden elastische Polyurethane mit hoher Härte erhalten. Die als Film präparierten Polyurethane wurden durch Zugprüfung und Dynamisch Mechanische Analyse (DMA) charakterisiert. Die Phasenstruktur ist abhängig von der Menge an Nanopartikeln, dem Isocyanatindex und dem Härtungsregime. Die Ergebnisse deuten daraufhin, dass die Nanopartikel, um einen typischen Nano-Effekt zu zeigen, von ähnlicher Größe sein müssen wie die Matrix, in die sie eingebettet sind. Die erhaltenen elastischen Polymere zeigen ungewöhnlich hohe Shore-D-Härten im Bereich von 70 und Zugfestigkeiten bis zu $47 \mathrm{MPa}$ bzw. Bruchdehnungen von $7 \%$.

\section{Abstract}

Based on a previously published (Peshkov 2011) synthesis route of nanoscale oligourea dispersion polyols (NODP) a new type of polyurethanes with a polyurea matrix was developed. Polyurethanes with high hardness and elasticity were prepared by reacting a formulation based on the NODP's and di- or polyisocyanates. The polyurethanes obtained as films were characterised by mechanical tests and dynamic mechanical analysis (DMA). The phase structure depends on the amount of nanoparticles present, the isocyanate index, and the mode of curing. It is suggested that nanoparticles have to be of similar size as the matrix into which they are embedded to show a typical nano-effect such as shown here. These elastic polymers show an unusual high Shore $D$ hardness of some 70 and tensile strength up to $47 \mathrm{MPa}$ at elongations at break of $7 \%$.

\section{Introduction}

Polyurethanes produced from NODP's are generally flexible foams and in some cases coatings. The microparticles in the polyols are used as internal reinforcements to result in higher ball rebound properties and lower densities of the foams.

Polyurethanes are known to have a multiphase morphology due to the low solubility of the aromatic isocyanates residues in the polyol phase and the ability to form strong intermolecular interactions, especially hydrogen bonds (Hespe 1972). Not only linear polyurethanes are able to segregate into distinct phases but also crosslinked polyurethanes exhibit such behaviour (Behrendt 1983). In crosslinked polyurethanes the degree of phase segregation depends strongly on the crosslink density, the solubility of the phases, and on the molecular weight of the soft segment and its degree of branching.
Nanoscale fillers usually change the morphology of polymers to a great extent (Vaia 2002), but in general only inorganic nanofillers have been investigated so far. These nanocomposites are, thus, two-phase systems consisting of polymers loaded with high-surfacearea reinforcing fillers (Vaia 2001). Organic nanofillers with particle sizes in the range of 5 to $100 \mathrm{~nm}$ have been rarely investigated.

Active nanofillers which can either react with one or more reactants or form physical bonds with structural units of the main chain have not yet been described. To achieve high load transfer between the filler and matrix the surface of the fillers is often functionalized, e. g. with a coupling agent (Brown 2005). Recently, a new synthesis route for new NODP's which contain between 5 and $20 \mathrm{wt} \%$ of oligoureas with dimensions of 20 to $400 \mathrm{~nm}$ has been described (Peshkov 2011). The oligourea particles exhibit on their surface as a result of the synthesis method free primary amino groups able to react with other suitable groups. 
In this paper we report on the preparation of polyurethane polyureas by formulation of new NODP's with the optional use of certain additives and their reaction with polyisocyanates, the results of mechanical testing of these polyurethane polyureas obtained as films, and on the investigation of the structure of these polymers by dynamic mechanical analysis (DMA).

\section{Materials and Methods}

The synthesis of the polyols was performed as described in (Peshkov 2011). To prepare the film samples reactants were used after drying by rotational evaporator at $130{ }^{\circ} \mathrm{C}, 0.1 \mathrm{mbar}$ for $3 \mathrm{~h}$.

Before preparation of the polyurethanes, hydroxyl compounds and polymeric 4,4'-diphenylmethane diisocyanate (pMDI) were carefully separately degassed at $100{ }^{\circ} \mathrm{C}$ at $0.1 \mathrm{mbar}$ for $1 \mathrm{~h}$ before mixing. The NODP or the formulated polyhydroxyl compounds were reacted at room temperature with p-MDI, (Lupranat ${ }^{\circledR}$ M20) by hand mixing in aluminium beakers. After mixing, the mixture was degassed another time for at least 30 s. If the pot life of the reaction mixture was shorter than 120 $\mathrm{s}, 0.3 \mathrm{wt} \%$ of acetyl acetone were used as a reaction inhibitor to establish a pot life of 120 to 180 s. The acetyl acetone remains in the mixture, no further degassing was performed.

The reaction mixture was poured on siliconized release paper in front of a knife of a Matis Labdryer ${ }^{\circledR}$. The knife is drawn slowly with a distance of 2 or $4 \mathrm{~mm}$ to the basic roll to give a film of 2 or $4 \mathrm{~mm}$ thickness and 25 to $25 \mathrm{~cm}$ area. The coated release paper is automatically introduced into the heating chamber and cured at $80^{\circ} \mathrm{C}$ for $60 \mathrm{~min}$. The film is automatically ejected from the Labdryer ${ }^{\circledR}$. It is cooled to ambient temperature, recovered from the release paper and stored at ambient conditions for $14 \mathrm{~d}$ before further testing.

A Zwick Universal Testing Machine Z20 was used for the stress - strain measurements to obtain the tensile strength and elongation at break values. Shore A and D hardness was tested according to DIN 53505.

DSC analyses were performed on a Netzsch DSC 204 employing a heating rate of $10 \mathrm{~K} / \mathrm{min}$.

DMA was carried out using a Myrenne ATM3 torsion pendulum at $1 \mathrm{~Hz}$ and a heating rate of about $1 \mathrm{~K} / \mathrm{min}$.

\section{Results}

For the polyurethanes produced the numeration of the polyols introduced in (Peshkov 2011) were used, extended by prefixed $\mathrm{F}$.

The dominant effect of the urea structures is shown by the hardness of the poly(urethane urea) films. The Shore-D-hardness of the samples is in the range of 70 as shown in table 1.

\begin{tabular}{|c|c|c|c|c|c|}
\hline Sample & $\begin{array}{l}\text { Shore } \\
\text { A }\end{array}$ & $\begin{array}{l}\text { Shore } \\
\text { D }\end{array}$ & $\begin{array}{l}\text { Tensile } \\
\text { strength } \\
\text { (MPa) }\end{array}$ & $\begin{array}{l}\text { Elongation } \\
\text { at break } \\
(\%)\end{array}$ & DEG : DPG \\
\hline F 1.1 & 97 & 68 & 23 & 1.2 & $100: 1$ \\
\hline F 1.2 & 98 & 74 & 42 & 3.4 & $90: 10$ \\
\hline F 1.4 & 96 & 70 & 47 & 3.5 & $70: 30$ \\
\hline F 1.5 & 96 & 75 & 45 & 3.9 & $60: 40$ \\
\hline F 1.6 & 98 & 75 & 38 & 2.0 & $50: 50$ \\
\hline F 1.7 & 99 & 70 & 38 & 4.4 & $40: 60$ \\
\hline
\end{tabular}

Tab. 1: Shore-D-hardness of the poly(urethane ureas) of the NODP series with increasing amount of DEG in the solvolysis mixture and Lupranat ${ }^{\circledast}$ M20S

As known, at a hardness of more than 95 Shore A it is out of its measuring range. The Shore-D shows very high values for polyurethanes containing about 45 $\mathrm{wt} \%$ of a long chain polyether alcohol. This proves the dominating effect of the oligourea domains in the polyurethane structure resulting in a very hard but elastic material. This unusual combination of mechanical properties can be explained by the morphology being dominated by the oligourea structures. The maximum hardness is found in polymers based on the NODP's of the smallest particles. Another effect is the incorporation of the polyether alcohols at least to a great extent into the oligoureas as a plasticizer. This model of plasticizing the oligourea phase could give the explanation of high hardness, high tensile strength, and high elongation at break with a maximum at sample F 1.7.

In this series of poly(urethane ureas) produced from the NODP's with systematic change of the DEG content the tensile strength increases from $23 \mathrm{MPa}$ of the poly(urethane urea) prepared from the solely DEG containing solvolysis mixture to $42 \mathrm{MPa}$ when adding only $10 \mathrm{wt} \%$ of DEG to the solvolysis mixture obtaining much smaller particles of the oligoureas (see table 2) 


\begin{tabular}{|l|l|l|l|l|}
\hline Sample & $\begin{array}{l}\text { Shore } \\
\text { D }\end{array}$ & $\begin{array}{l}\text { Tensile } \\
\text { strength } \\
\text { (MPa) }\end{array}$ & $\begin{array}{l}\text { Elongation } \\
\text { at break } \\
(\%)\end{array}$ & $\begin{array}{l}\mathrm{M}_{\mathrm{n}} \text { of the } \\
\text { polyethylene oxide }\end{array}$ \\
\hline F 1.2 & 74 & 42 & 3.4 & 102 \\
\hline F 2.1 & 76 & 34 & 4.0 & 200 \\
\hline F 3.1 & 72 & 28 & 5.0 & 600 \\
\hline
\end{tabular}

Tab. 2 Mechanical properties of polyurethane films prepared of NODP's with increasing chain length of the polyethylene oxide (DPG : PEG $90: 10$ )

The strength value nearly remains constant in the poly(urethane ureas) of the mixtures increasing in the DEG content up to about $40 \mathrm{wt} \%$.

The values of the poly(urethane ureas) made with DPG only show a low elongation at break in the range of $1 \%$. Increasing the DEG content leads to a sharp increase of the elongation values with a maximum in the poly(urethane urea) film produced with $60 \mathrm{wt} \%$ of DEG (sample F1.7). The mechanical properties will find their explanation in the morphological structure described in the forthcoming discussion. The smaller the particle size of the oligoureas incorporated into the polymer chain and their position as nanoscale fillers between adjacent chains and the higher the amount of DEG the higher is the degree of phase mixing. As seen from the shift of the main transition region to higher $\mathrm{T}_{\mathrm{g}}$, the better is the formation of the rigid segregated phase. A higher degree of phase mixing leads to less sharp phase boundaries enabling forces to be easier transmitted within the structure and hindering break. The better the flexible part of the soft domains is developed the higher is the elongation at break. In the case of the morphology of this type of polymers a greater part of the soft phase is incorporated into the rigid domains. This leads to a plasticizing effect in the polymer through the action of free polyether aggregates within the rigid domains.

Increasing the chain length of the polyethylene oxide shows a decrease in the mechanical characteristics like hardness and strength as depicted in table 3.

\begin{tabular}{|c|c|c|c|c|}
\hline Sample & $\begin{array}{l}\text { Shore } \\
\text { D }\end{array}$ & $\begin{array}{l}\text { Tensile } \\
\text { strength } \\
\text { (MPa) }\end{array}$ & $\begin{array}{l}\text { Elongation } \\
\text { at break } \\
(\%)\end{array}$ & $\begin{array}{l}M_{n} \text { of the } \\
\text { polyethylene oxide }\end{array}$ \\
\hline F 1.4 & 70 & 47 & 3.5 & 102 \\
\hline F 2.2 & 70 & 31 & 8.0 & 200 \\
\hline F 3.2 & 68 & 17 & 15.0 & 600 \\
\hline
\end{tabular}

Tab. 3: Mechanical properties of poly(urethane urea) films prepared of NODP's with increasing chain length of the polyethylene oxide (DPG : PEG 70 : 30)
With increasing the molecular weight of the polyethylene glycol in the solvolysis mixture the effect of the morphological structure as deduced from DMA is reflected in the mechanical properties (see table 3 ).

The Shore D hardness gradually decreases as does the tensile strength. The elongation at break increases as well showing an increase in elasticity. When referring to the glass transition temperatures of the rigid phase as shown in figure 1 , the gradual decrease of the $\mathrm{T}_{\mathrm{g}}$ maximum and the broadening of the $\mathrm{T}_{\mathrm{g}}$ region is obviously correlated to the decrease in strength, i.e. the effect of the nanoparticles, and the increase of the elongation at break, i.e. the better phase mixing.

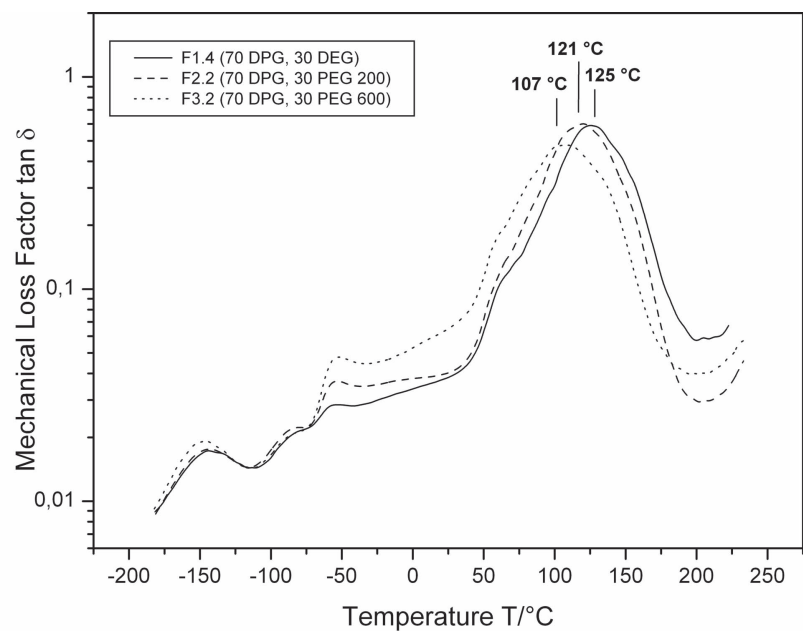

Fig. 1: Mechanical loss factor of polyurethanes based on NODP's with increasing molecular weight of PEG's and pMDI

When increasing the amount of the polyethylene glycols (PEG's) to a ratio of DPG : PEG of 70: 30 the effects discussed based on the poly(urethane ureas) made at a ratio of $90: 10$ are strengthened. This is seen from the tensile strength decreasing from 47 to $17 \mathrm{MPa}$ and simultaneously the elongation at break increasing from $3.5 \%$ to $15 \%$ showing that the formulation with PEG 600 is on the verge to a true elastomer.

Substituting the DPG by butane-1,4-diol and increasing the amount of DEG systematically, the effect of the DEG is smaller than in the case of DPG. Butane-1,4-diol as a chain extender is known to lead to the best possible molecular fitting of it's rigid domains with MDI while in the case of DPG this fitting is interfered both by the chain length of the glycol and the methyl side groups. The data of this series as depicted in table 4 show a correlation of the mechanical properties to the composition of the poly(urethane ureas) in a similar way as in the series with DPG and DEG. 


\begin{tabular}{|c|c|c|c|c|c|}
\hline Sample & $\begin{array}{l}\text { DEG } \\
(w t \%)\end{array}$ & $\begin{array}{l}\text { Shore } \\
\text { D }\end{array}$ & $\begin{array}{l}\text { Tensile } \\
\text { strength } \\
\text { (MPa) }\end{array}$ & $\begin{array}{l}\text { Elongation } \\
\text { at break } \\
(\%)\end{array}$ & $\begin{array}{l}\text { Elastic } \\
\text { (tensile) } \\
\text { modulus } \\
\text { (MPa) }\end{array}$ \\
\hline F 6.5 & 10 & 70 & 34 & 2.0 & 1915 \\
\hline F 6.4 & 20 & 75 & 28 & 1.7 & 1830 \\
\hline F 6.3 & 30 & 72 & 29 & 2.0 & 1570 \\
\hline
\end{tabular}

Tab. 4: Mechanical properties of polyurethane films prepared of NODP's with mixtures of butane-1,4-diol and DEG in the solvolysis mixture

The Shore D hardness is nearly constant which maybe attributed to the better phase formation ability of the butane-1,4-diol. The elongation at break is nearly constant as well. The only larger differences are seen in the tensile strength with a marked decrease on increasing the DEG content more explicitly as in the DPG : DEG series.

In another series, the amount of flexible foam in the reaction mixture was varied and with this both the hydroxyl content, the concentration of polyether triol, the concentration of ethylene oxide blocks, and the concentration of oligoureas. The amount of oligoureas present in the NODP's increases from ca. $11 \mathrm{wt} \%$ to about $18 \mathrm{wt} \%$. The mechanical properties of films produced from these NODP's with p-MDI under the same conditions employing a ratio of DPG: DEG of 40: 60 are depicted in table 5 .

The data of table 5 show the decrease in hardness and parallel the increase in elongation at break. In these poly(urethane ureas) the concentration of the oligoureas increases together with a slight increase of the content of polyether alcohol. Another effect is the loss of the stabilizing ability of the ethylene oxide of the DEG with decreasing its amount. Furthermore, the oligoureas tend to agglomerate to a greater extent at higher concentrations giving rise to larger particles and to an increasing instability of the systems. Finally, a NODP with $73 \mathrm{wt} \%$ of flexible foam (corresponding to approximately $21 \%$ of oligoureas) could not be handled anymore to produce polyurethanes from it as both the viscosity was too high for that purpose and the polyol tended to split into two phases. Any attempt to increase this amount in the system leads to larger oligourea particles both from reaction and through agglomeration.

The effect of the isocyanate index $\mathrm{I}_{\mathrm{NCO}}$ as defined by $\mathrm{I}_{\mathrm{NCO}}=\mathrm{EQ}_{\mathrm{NCO}}{ }^{*} 100 / \mathrm{EQ}_{\mathrm{OH}}$ in which $\mathrm{EQ}_{\mathrm{NCO}}$ is the isocyanate equivalent and $\mathrm{EQ}_{\mathrm{OH}}$ the hydroxyl equivalent was shown using NODP 1.7 with a combination of $60 \mathrm{wt} \%$ of DEG and $40 \mathrm{wt} \%$ of DPG in the solvolysis mixture. The stoichiometry of the poly(urethane urea) film F 1.7 was calculated using the hydroxyl number only (330 $\mathrm{mg} \mathrm{KOH} / \mathrm{g}$, hydroxyl equivalent $170 \mathrm{~g}$ /equivalent). The amine number was determined to be $55 \mathrm{mg} \mathrm{KOH} / \mathrm{g}$. This amine number is a sum of all amines present in the mixture forming salts with perchloric acid in the course of the analytic determination. The amine number results from

- primary amino groups from the decomposition reaction mainly on the outer shell of the oligoureas and to a very small extent of monomers such as MDA,

- secondary amino groups both from the reaction being bond to the outer shell of the oligoureas and from some very small excess of the reagent DBA,

- tertiary amino groups from the catalysts originally present in the foam formulation and in end groups of substituted oligoureas.

Thus, it is the sum of the secondary aliphatic amines, the tertiary amine catalysts, primary aromatic amino groups, and the amino groups of the oligoureas. To calculate the reactive part $(\mathrm{NH})$ towards isocyanates the amine number has to be decreased by subtracting the tertiary amines present in the NODP which was calculated to correspond to an amine number of $27 \mathrm{mg}$ $\mathrm{KOH} / \mathrm{g}$ thus giving an effective amine number of $28 \mathrm{mg}$ $\mathrm{KOH} / \mathrm{g}$ in case of this NODP. The recalculation of the isocyanate index corresponding to the total of reactive groups is consequently approximately 72 . Based on the hydroxyl equivalent of $170 \mathrm{mg} \mathrm{KOH} / \mathrm{g}$ formulations

\begin{tabular}{|c|c|c|c|c|c|c|}
\hline Sample & Foam (wt\%) & $\begin{array}{l}\text { Calculated urea } \\
\text { content (\%) }\end{array}$ & Shore D & $\begin{array}{l}\text { Tensile strength } \\
\text { (MPa) }\end{array}$ & Elongation at break (\%) & $\begin{array}{l}\text { Elastic (tensile) modulus } \\
\text { (MPa) }\end{array}$ \\
\hline F 1.7 .5 & 53 & 11.1 & 80 & 39 & 2.0 & 2130 \\
\hline F 1.7.4 & 58 & 12.2 & 75 & 30 & 1.9 & 1880 \\
\hline F 1.7.0 & 63 & 13.3 & 70 & 38 & 4.4 & 1630 \\
\hline F 1.7.6 & 68 & 14.3 & 68 & 19 & 16 & 760 \\
\hline F 1.7.7 & 73 & 15.3 & - & - & - & - \\
\hline
\end{tabular}

Tab. 5: Mechanical properties of polyurethane films made of NODP's with increasing amount of flexible foam in the solvolysate and p-MDI 


\begin{tabular}{|c|c|c|c|c|c|c|}
\hline Sample & $\begin{array}{l}\text { Hydroxyl isocyanate } \\
\text { index }\end{array}$ & $\begin{array}{l}\text { Actual isocyanate } \\
\text { index }\end{array}$ & $\begin{array}{l}\text { Shore D } \\
\text { hardness }\end{array}$ & $\begin{array}{l}\text { Tensile strength } \\
\text { (MPa) }\end{array}$ & $\begin{array}{l}\text { Elongation at } \\
\text { break }(\%)\end{array}$ & $\begin{array}{l}\text { Elastic (tensile) } \\
\text { modulus (MPa) }\end{array}$ \\
\hline F 1.7.0 & 100 & 72 & 70 & 38 & 4.4 & 1630 \\
\hline F 1.7.105 & 105 & 75 & 70 & 34 & 4.8 & 1570 \\
\hline F 1.7.110 & 110 & 79 & 70 & 36 & 7.0 & 1140 \\
\hline F 1.7.115 & 115 & 83 & 70 & 32 & 2.4 & 1680 \\
\hline F 1.7.125 & 125 & 96 & 75 & 36 & 3.3 & 1860 \\
\hline
\end{tabular}

Tab. 6: Mechanical properties of films with increasing isocyanate hydroxyl index

with higher indexes were developed and films cast. In table 6 some of the mechanical properties of these poly(urethane ureas) are presented.

An increase in the actual isocyanate index to 96 or a hydroxyl isocyanate index of 125 is still less than the stoichiometric amount of isocyanate to compensate for the total of reactive groups. An isocyanate index calculated on the hydroxyl number only will need 132 to meet the point of stoichiometry. These findings correspond to the results of the DMA showing even at the hydroxyl isocyanate index of 125 still a weak maximum in the range of $-60^{\circ} \mathrm{C}$.

The increase in isocyanate index has a lesser effect on the mechanical properties of the films. The Shore $\mathrm{D}$ hardness is increased only at nearly stoichiometric conditions, the tensile strength is constantly on a lower level than with the original formulation at an index of 72 confirming earlier results (Langenstraßen 2001). The elongation at break shows a tendency to decrease due to the higher amount of rigid domains and crosslinking, the modulus of elasticity (derived from tensile measurements) passes through a minimum at a hydroxyl isocyanate index of 110 .

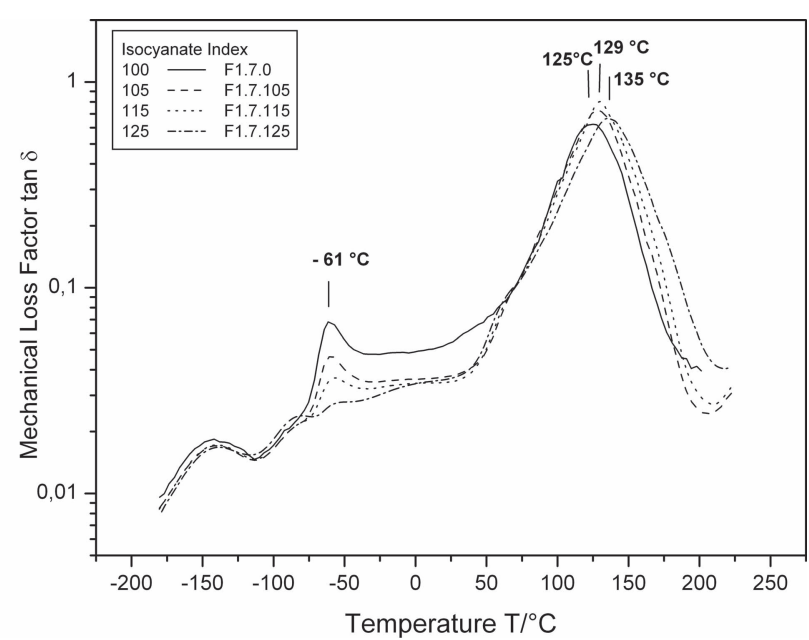

Fig. 2: DMA of polyurethanes based on an NODP with $60 \mathrm{wt} \%$ of DEG in the solvolysis mixture and increasing isocyanate index
As presented in the DMA curves (see figure 2) the course of the $\tan \delta$ is not fitting into the series of curves tending to be closer to the higher index poly(urethane urea) in the region between -30 and $+40{ }^{\circ} \mathrm{C}$ showing a high degree of phase mixing. This is supported by the broader main transition region between +50 and $+150{ }^{\circ} \mathrm{C}$ with the lower temperature shoulder shifted from 65 to $78{ }^{\circ} \mathrm{C}$. This shows that in the low molecular weight glycol urethane phase are incorporated increasing amounts of the more rigid domains. Further, this leads to the assumption that at certain lower isocyanate indexes a better phase mixing is found and with an increasing isocyanate index the elastic properties of the films are not generally improved with respect to their mechanical properties.

In a first series of experiments the NODP's with mixtures of DEG and DPG having an oligourea content of $13.3 \mathrm{wt} \%$ were used to produce poly(urethane urea) films suitable for DMA measurements.

When increasing the percentage of DEG in the NODP from 0 to $60 \mathrm{wt} \%$ not only the viscosity of the resultant polyol decreases but also in the morphology of the poly(urethane ureas) changes were found (see figure 3).

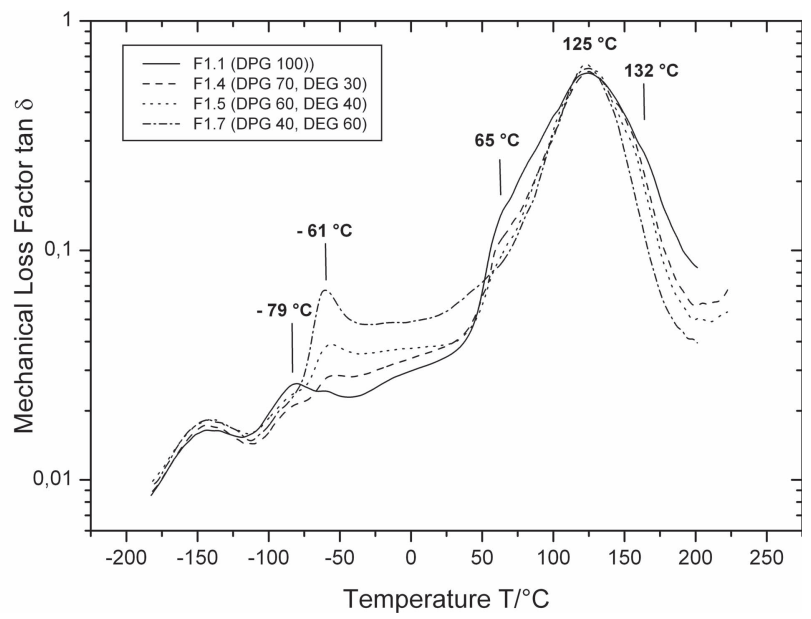

Fig. 3: Mechanical loss factor of polyurethane films produced from NODP's with variation of the DEG and DPG content in the solvolysis mixture and pMDI 
The $\tan \delta$ curves of the DMA show a decreasing height of the relative maximum at about $-80{ }^{\circ} \mathrm{C}$ which is considered to be the $\beta$-transition. It decreases gradually and shifts slowly to lower temperatures. Simultaneously, a second low temperature maximum appears at about $-60{ }^{\circ} \mathrm{C}$ and increases in intensity with increasing content of DEG. It is seen as a strong maximum at $-61{ }^{\circ} \mathrm{C}$ in the mixture containing $60 \mathrm{wt} \%$ of DEG. This maximum is attributed to a free or only singularly bound polyether polyol phase in the polymer. Another but small maximum is observed at about $-5{ }^{\circ} \mathrm{C}$ with decreasing intensity when increasing the amount of DEG. The slope of the loss factor curve decreases gradually becoming a parallel to the temperature axis at $60 \mathrm{wt} \%$ DEG in the NODP. A fourth maximum is observed in the region of $65{ }^{\circ} \mathrm{C}$ usually as a shoulder. It is most pronounced in the poly(urethane urea) based on DPG as the solvolysis reagent and gradually disappears so that it is only a very weak shoulder in the poly(urethane urea) with $60 \mathrm{wt} \%$ DEG in the solvolysis mixture. This shoulder is attributed to a phase formed from DPG and p-MDI (the glass transition temperature of a sample produced only from DPG and MDI is found at $68^{\circ} \mathrm{C}$ ). The glass transition of the continuous phase is found between 107 and $125^{\circ} \mathrm{C}$. The width of the maximum decreases with a slight shift to higher temperatures, or a weak shoulder on the high temperature flank of the loss factor curve occurs. When examining the samples after measurement, no changes or decomposition were observed so that the slight increase of the loss factor curve beyond $200{ }^{\circ} \mathrm{C}$ has to be considered as a consequence of the crosslinked structure of the poly(urethane urea).

The percentage of the tertiary amine in the NODP is about $0.5 \mathrm{wt} \%$ which corresponds to an amine number of about $27 \mathrm{mg} \mathrm{KOH} / \mathrm{g}$. The amine number has to be reduced by this number to give the reactive amino groups. Considering this and the high reactivity of both primary and secondary amino groups towards isocyanate groups leads to the conclusion that the calculation of the stoichiometry only by the hydroxyl groups as determined by hydroxyl number analysis leads to understoichiometric ratios in the poly(urethane ureas) and, thus, to isocyanate indexes below 85 .

The course of the $\tan \delta$ curve between -50 and $+40{ }^{\circ} \mathrm{C}$ is explained by mixed phases of the short and long chain poly(ether urethanes). As described in the first paragraph, the dissolution ability of the polyol mixture for oligoureas increases with increasing DEG content so that with increasing the DEG content simultaneously phase mixing increases. The transition temperature found in the range of $-45^{\circ} \mathrm{C}$ is, hence, attributed to the transition of the long chain polyether urethane phase while that characterized as a shoulder at $+65{ }^{\circ} \mathrm{C}$ can be attributed to the $\mathrm{T}_{\mathrm{g}}$ of the urethane based on DPG and p-MDI. The region between these two recognizable transitions is that of mixed phases of the various urethane group containing species with different chain lengths of the polyether chain and degrees of aggregation. The phase separation of urethanes of different chain lengths is never complete but in general some mixed phases occur.

The main transition at temperatures above $100{ }^{\circ} \mathrm{C}$ is assumed to be based on that of the oligoureas which are the continuous phase and form part of the main chain as well as coil structures of high rigidity. The urea phase determines the molecular structure of the polymer and its $\mathrm{T}_{\mathrm{g}}$. The $\mathrm{T}_{\mathrm{g}}$ of a fully developed continuous phase is higher than the curing temperature so that by further curing at higher temperature changes in structure and, consequently, in the DMA curves maybe assumed (fig. 4).

In the poly(urethane ureas) of these solvolysis products with p-MDI the effect of the chain length of the PEG has several effects on the properties of the poly(urethane ureas) and their DMA curves as shown in figure 2 .

It can be seen from figure 2 that the peak height of the low temperature transition at about $-60^{\circ} \mathrm{C}$ increases with increasing molecular weight of the PEG. This suggests a better phase separation by DEG and a more extensive phase mixing by increasing the molecular weight of the PEG and a better solubility of the oligoureas in the polyethylene oxide segments. This is shown by the increase in the mechanical loss factor of the DMA of the poly(urethane urea) sample based on the NODP with PEG 600. The transition at $65^{\circ} \mathrm{C}$ is seen again as a shoulder. This shoulder is best represented in the curve of the sample prepared with DEG. Increasing the molecular weight of the PEG's leads to weaker shoulders in the $\tan \delta$ curve and to a shift to higher loss factors. Since the amount of DPG present in the formulation is kept constant this supports the assumption that with increasing amount of ethylene oxide in the polyether chain or by increasing the block length of the polyethylene oxide in the polyether the tendency of phase mixing increases due to the better solubility of the rigid domains in the soft segment phase.

The $\mathrm{T}_{\mathrm{g}}$ of the urea phase in the poly(urethane ureas) is shifted from $125^{\circ} \mathrm{C}$ with DEG in the NODP to $107^{\circ} \mathrm{C}$ 
with PEG 600 in the NODP. When increasing the molecular weight of the PEG's a weak high temperature shoulder appears above $130{ }^{\circ} \mathrm{C}$ which shifts from 165 ${ }^{\circ} \mathrm{C}$ in the sample made with DEG to about $130^{\circ} \mathrm{C}$ in the sample made with PEG 600. Additionally, the normalized value of the storage modulus in the rubber plateau region decreases gradually to half of the maximum value when increasing the molecular weight of the PEG (figure 2).

The increase in molecular weight of the PEG's is mainly directed to a more intense phase mixing and a less sharp segregation of the soft and hard segment phases. As the phase segregation is hindered by the crosslinking in the rigid segments due to the isocyanate functionality of the p-MDI used (this is in the range of 2.85 ) the better solubility of the oligoureas present in the increased amount of ethylene oxide units in the polymer main chain leads to better phase mixing. The larger particle size of the oligoureas effects the phase behaviour as indicated by DMA much less than the structure of the polyols present. In this respect, the question »how nano are nanocomposites« (Schaefer 2007) has to be answered.

The increase in the isocyanate index leads actually to a more complete reaction of the hydroxyl compounds. As the index was calculated on the basis of the hydroxyl numbers only not taking into consideration the free amino groups being available on the oligourea particles it was shown on this way that the oligourea particles always take part in the reaction. Thus, they are active nanofillers which are built into the polymer chain. The shift of the $T_{g}$ of the urea phase to higher temperatures and the increase in the level of the rubber plateau in the G' curves support this view. With a higher degree of conversion in the reaction of the isocyanate groups with both the hydroxyl and amine groups and the corresponding higher crosslink density a higher degree of phase separation in the low temperature region is produced not affecting a possible phase separation in the high temperature range. The high crosslink density expressed as a low $M_{c}$ average value does not prevent phase separation. This maybe attributed to the large differences in the $M_{c}$ values being in the range of 370 in case of two MDI molecules connected by one of the glycols and 4000 in case of the reaction of two polyether chains with an MDI molecule.

When subjecting a sample of the material produced with an isocyanate hydroxyl index of 125 (sample F1.7125 ) to a second run in the DMA the DMA curves com- pletely change (see figure 4). The original sample was cured at $80{ }^{\circ} \mathrm{C}$ for $1 \mathrm{~h}$. After the first run in the ATM3 up to $230^{\circ} \mathrm{C}$ with about $1 \mathrm{~K} / \mathrm{min}$ it was "postcured « at a temperature higher than the $\mathrm{T}_{\mathrm{g}}$ of $135^{\circ} \mathrm{C}$ for about 120 min. The final temperature of $230{ }^{\circ} \mathrm{C}$ is surpassing the cleavage temperature of the urethane groups both of secondary and primary hydroxyl groups with aromatic isocyanates which is generally assumed to be in the range of 180 to $210{ }^{\circ} \mathrm{C}$ (Saunders 1967). This leads to the assumption that some of the urethane groups are cleaved above $200{ }^{\circ} \mathrm{C}$ in a reverse formation reaction and set free more isocyanate groups which in turn may further react. The result of such an assumption is seen in the loss factor curve (figure 4).
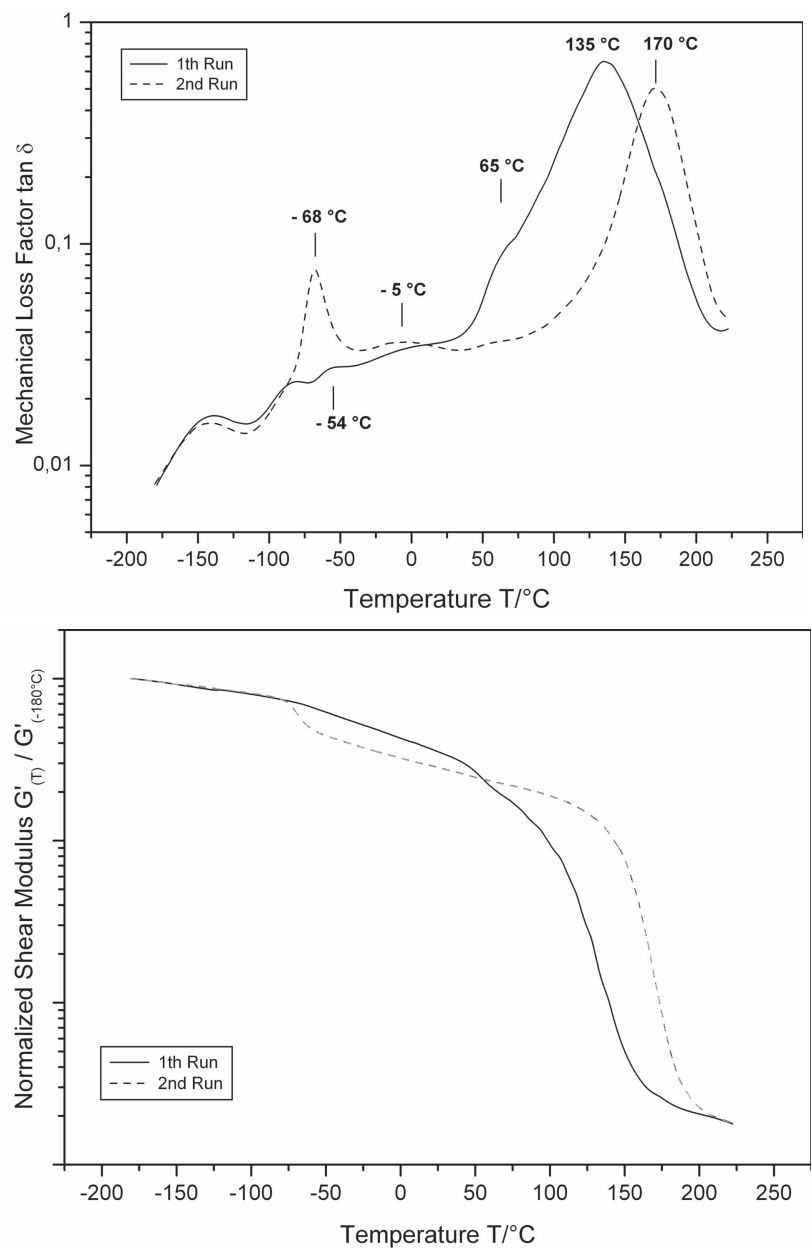

Fig. 4: First and second run of F 1.7-125 sample with isocyanate index 125 based on hydroxyl content, a) Loss factor, b) Storage modulus G'

The loss factor curve of figure $4 \mathrm{a}$ shows the original $\mathrm{T}_{\mathrm{g}}$ at $-54^{\circ} \mathrm{C}$ corresponding to that of the polyether urethanes which nearly vanishes in the second run. Instead, a $\mathrm{T}_{\mathrm{g}}$ appears now at $-68^{\circ} \mathrm{C}$ being attributed to a free polyether alcohol phase as discussed above. A weak maximum appears again at $-5^{\circ} \mathrm{C}$ but more pronounced 
in the post-cured sample showing a higher degree of phase mixing of the urethanes and a clearer effect of the more thermally stable short diol based polyurethanes. The shoulder at $+65^{\circ} \mathrm{C}$ is now a very weak maximum which shows that a glycol urethane phase is present to some extent. The glass transition region of the urea phase has but shifted from originally $135^{\circ} \mathrm{C}$ to the high value of $170^{\circ} \mathrm{C}$ and is less broad. This is a proof of a much higher crosslink density of the material being explained by two paths of reaction: (1) the urea groups formed on the surface of the oligourea particles of the continuous phase by reaction of free amino groups and isocyanate groups are stable throughout the thermal process and become dominant, (2) the originally present polyether urethanes are cleaved into polyether alcohol and isocyanate (reverse reaction of urethane formation) and the resulting isocyanates together with possibly available excess isocyanate groups react with themselves to form thermal stable isocyanurate groups by trimerisation. Both paths lead to higher crosslink density by thermally stable groups: the urea groups are known to be cleaved only at temperatures above 235 ${ }^{\circ} \mathrm{C}$, the isocyanurate groups above $375{ }^{\circ} \mathrm{C}$ (Saunders 1967). The polymer structure is now determined by a continuous urea phase with some additional isocyanurate groups and the polyether alcohol as a plasticizer and some linear glycol urethanes as connecting structural units forming their own phases at -+5 and $65^{\circ} \mathrm{C}$. This model is further supported by the increase of the absolute value of the loss factor in the high temperature region and by the shape of the storage modulus curve as shown in figure $4 \mathrm{~b}$.

\section{Discussion of results}

NODP's are suitable to formulate flexible, semi flexible, and rigid polyurethanes, especially coatings on their basis. These NODP's when reacted with suitable diisocyanates or polyisocyanates result in polyurethanes with extraordinary properties (Peshkov 2006).

If such two component systems are reacted in the absence of foaming agents under film forming conditions coatings with exceptional high mechanical (e. g. tensile strength of more than $45 \mathrm{MPa}$ at $8 \%$ elongation of break) and thermo-mechanical properties (the glass transition temperature can be extended up to $175^{\circ} \mathrm{C}$ ) at a Shore-D-hardness of 75 are obtained (Langenstraßen 2001) which maybe used as leather or textile coatings.
The NODP's synthesized as described by solvolysis of HR polyurethane foams (polyurethane polyureas) were reacted with polymeric MDI to give a new type of poly(urethane urea) with the oligoureas built into the main chain of the polymers and the polyureas - if present-forming active fillers arranged in the side chain together forming a continuous phase despite their low amount of some 10 to $16 \mathrm{wt} \%$. Thus, the poly(urethane ureas) with a broad distribution of the molecular weight between crosslinks $M_{c}$ in the urethane phase ranging between about 370 and $4000 \mathrm{D}$ shows despite this crosslinking a distinct phase structure.

The most interesting areas are (1) in the low temperature region of the $\tan \delta$ curves where it could be shown that despite a calculated isocyanate index of 100 based on hydroxyl groups at least part of the polyether alcohol is present in free form and did not react with the isocyanate. The $\mathrm{T}_{\mathrm{g}}$ of polyether alcohols of molecular weight of about 5500 with about $13 \%$ of ethylene oxide endblocks was determined to be $-67^{\circ} \mathrm{C}$, that of polypropylene ether triols of molecular weight 3000 to be $-61{ }^{\circ} \mathrm{C}$. The $\mathrm{T}_{\mathrm{g}}$ of the urethanes based on MDI and both types of polyether alcohols are in the region of -46 to $-44^{\circ} \mathrm{C}$. The polyether alcohol should, therefore, be free to such an extent as determined by the reaction conditions and the components involved and act as a plasticizing phase. When the poly(urethane ureas) are produced at rather low temperatures (mainly $80^{\circ} \mathrm{C}$ ) it is suggested that a free polyether alcohol phase is present in the samples and organized into a segregated phase. By heating the material to temperatures exceeding the originally found $\mathrm{T}_{\mathrm{g}}$ this phase segregation is improving and leads to a much better structured polyether alcohol phase. It is suggested that this polyether alcohol phase is organized in the "free space « between the bulky oligourea particles of the continuous phase.

The second transition (2) was always found to be beyond $100{ }^{\circ} \mathrm{C}$ depending on the composition of the solvolysis mixture only. When higher amounts of ethylene oxide are present in the poly(urethane urea) the phase separation is hindered due to better solubility of the aromatic urea groups in the polyol mixture. Nevertheless, phase separation occurs in all poly(urethane ureas) produced to a more or lesser extent.

All of the poly(urethane ureas) produced were cured at $80{ }^{\circ} \mathrm{C}$, i.e. below the main transition region. This leads to such a thermodynamic situation in the polymers that the polymer is frozen in before it could reach the energetic optimum. When heated above $\mathrm{T}_{\mathrm{g}}$ of the 
rigid phase movements of the structural units may occur again and lead to a re-formation of the structures, another degree of phase segregation and to other phases. In an experiment with two runs of the same sample this could be demonstrated. The poly(urethane urea) does not only reshape in its morphology but starts a set of reactions at temperatures above $200{ }^{\circ} \mathrm{C}$ even during short time intervals without showing any signs of thermal damage. In this second run it could be seen that the urethane groups at least partly cleave into hydroxyl and isocyanate compounds and the latter trimerize to form isocyanurate rings. The high thermal stability of both polyureas and isocyanurates with thermal decomposition temperatures higher than $240{ }^{\circ} \mathrm{C}$ is shown in a shift of the glass transition region from 135 to $170{ }^{\circ} \mathrm{C}$, in other samples up to $185^{\circ} \mathrm{C}$.

Based on the results of the DMA investigations a model of the morphology formed in the poly(urethane ureas) based on the new NODP's is proposed: the aggregated oligoureas or polyureas present in the material form supermolecular aggregates of themselves without involvement of the urethanes or the soft segments. They form the continuous phase where the urethanes act as connecting »hinges« and the polyether polyol molecules as a plasticizing phase in the free spaces left by the bulky oligo- or polyureas. This is confirmed by the interpretation of the DMA curves. Thus, the polyether segments are not playing a considerable role in structure formation but are more or less a plasticizer in the aggregated rigid polyurea domains.

The question as asked in (Schaefer 2007) can be answered to some extent in case of macromolecular systems. Based on the calculation of the oligourea dimensions being of at least $8 \mathrm{~nm}$ the nanoscale particles cannot be smaller but have to be larger. The average of the oligourea length distribution of 4 to 6 structural units allows it to calculate the smallest particle size in the range of $20 \mathrm{~nm}$. Some aggregation will occur also under mild or optimum conditions. Thus, the formation of the smallest aggregates are formed with a particle size to $60 \mathrm{~nm}$ and more by combining two or three of the smallest oligourea particles. Such aggregates are, thus, in the lower range of the average size of the oligourea particles. It is established by the investigation of mechanical properties and DMA that these have the greatest effect even at low concentration on the properties of the polymers formed. If decreasing the amount of the nanoparticles to $3.85 \mathrm{wt} \%$ (see figure 5) the $\mathrm{T}_{\mathrm{g}}$ in the polyurethane polyurea is shifted to $93 \mathrm{C}$.

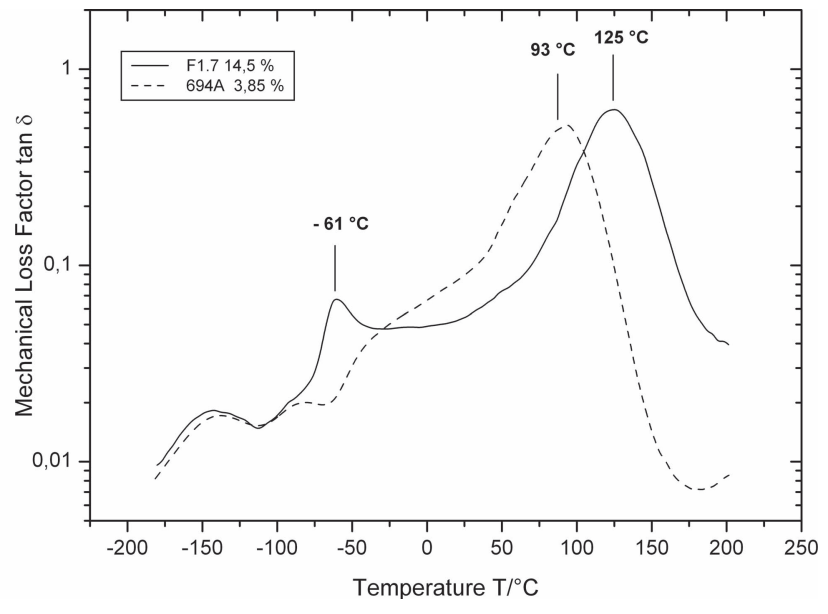

Fig. 5: Mechanical loss factor curves of samples with different oligourea content

Comparing the course of the loss factor $\tan \delta$ of sample 694 (Hunger 2010) to the polymer 1.7 shows not only this shift of more than $30 \mathrm{~K}$ but also that the transition regions of the formerly defined struct ures are completely reshaped. The low temperature region at $-61{ }^{\circ} \mathrm{C}$ is less pronounced, the transition of the poly(ether urethane) is incorporated into the flank, the interphase region is much stronger, the transition at $+65^{\circ} \mathrm{C}$ is weak, and no shoulder in the high temperature flank is to be seen. Thus, the model of the morphology developed and the results of the experiment described above let us assume that the effect of nanoparticles generally depends on the matrix into which they are embedded. In case of metals, several hundred of atoms need to form a nanoscale particle; in case of simple inorganic molecules at least some ten molecules are needed. In case of macromolecules such as in polymers they are themselves in the upper nanoscale range so that nanoscale particles in a lower range will have a distinct effect on material properties.

By comparing the poly(urethane ureas) with different content of oligoureas it was shown that the effect of increasing this content by about $10 \mathrm{wt} \%$ is much higher than it could be by only incorporating the same amount of urea groups by a typical aromatic diamine hardener (e. g. MOCA or MDA). In this case the increase in $\mathrm{T}_{\mathrm{g}}$ would be less than $10 \mathrm{~K}$ under similar conditions and showing clearly that the effect observed is a result of the nanoscale oligoureas present.

These results answer the question of (Schaefer 2007) in such a way as in organic/organic (macromolecular) systems with strong interactions between the segregated phases the nanoparticles are allowed to be effective in a particle range up to more than $100 \mathrm{~nm}$ showing still a typical $»$ nanoeffect $«$. 
By curing the poly(urethane ureas) based on the new types of NODP's with the oligoureas in the range of 20 to $200 \mathrm{~nm}$ one is able to form only by applying different temperature regimes in the curing cycle more elastic or more rigid polymers. By increasing the temperature above the glass transition (e. g. to $180^{\circ} \mathrm{C}$ ) it is possible to obtain high temperature stable polymers with incorporated and via physical bonds fixed plasticizers. Such materials are valuable as specialty polyurethanes being used as coatings or high temperature resistant foams. A forthcoming publication will report on the use of these materials as coatings of leather and other substrates (Peshkov 2008).

\section{Acknowledgements}

V.P. gratefully acknowledges support of BOSIG Baukunststoffe $\mathrm{GmbH}$ for gifts of polymeric 4,4'-diphenylmethane diisocyanate (pMDI)

\section{Bibliography}

Peshkov, V., Evtimova, R., Herzog, M., Behrendt, G. (2011): New Synthesis Route for PHD Polyols. Wissenschaftliche Beiträge 2011, TH Widau.

Hespe, H., Meisert, E., Eisele, U., Morbitzer, L., Goyert, W. (1972): Kolloid Polym. Z., 250: 797.

Behrendt, G., Goering, H., Pohl, G. (1983): Effect of soft segment crosslinking on the properties of elastic polyurethanes. IUPAC MACRO '83, Bucuresti.

Vaia, R. A. (2002): Polymer nanocomposites open a new dimension for plastics and composites. The AMPTIAC Newsletter, 6: 17-24.

Vaia, R. A., Giannelis, E. P. (2001), MRS Bull, 26: 394-401.

Brown, J. M., Anderson, D. P., Justice, R. S., Lafdi, K., Belfor, M., Strong, K. L., Schaefer, D. W. (2005): Polymer, 46: 10854-10865.

Langenstraßen, R., Huth, H., Pohl, M., Schmidt, K.-H., Goering, H., Ivanyi, S., Behrendt, G. (2001): Coatings Prepared from Polyurethane Flexible Foam Recycling Polyols. Paper presented at Polyurethanes EXPO 2001, Salt Lake City.

Saunders, J. H. (1967): Thermal Degradation and Flammability of Polyurethane Foams. In: Cellular Plastics, Natl. Acad. Sci. Publ. No. 1462, Washington, 123.

Peshkov, V., Naber, B. W., Schmidt, K.-H., Behrendt, G. (2006): Verfahren zur Herstellung neuer, flammgeschützter Polyurethane. DE-Anm. 102006058400.7 (07. 12. 2006).

Schaefer, D. W., Justice, R. S. (2007): Macromolecules. 40:8501-8517. Hunger, H.-D. (2010): Sample 694 was provided by courtesy of H.-D. Hunger of Performance Chemicals GmbH.

Peshkov, V., Klockemann, W. (2008): Neue Polyurethan-Beschichtungen. EP-Anm. 102008043824.3 (20. 09. 2008).

\section{Authors}

Dipl.-Ing. Vladimir Peshkov

University of Chemical Technology and Metallurgy

8 Kl. Ohridski bul.

1756 Sofia, Bulgaria

$\mathrm{T}+35926254101$

peshkov@uctm.edu

Prof. Dr. rer. nat. Gerhard Behrendt

Fachbereich Ingenieurwesen/Wirtschaftsingenieurwesen

Technische Hochschule Wildau [FH]

$\mathrm{T}+493375$ 508-591

gerhard.behrendt@th-wildau.de

\section{Prof. Dr. Rozeta Evtimova}

University of Chemical Technology and Metallurgy

8 Kl. Ohridski bul.

1756 Sofia, Bulgaria

$\mathrm{T}+35926254101$

evtimova@uctm.edu

\section{Prof. Dr. rer. nat. Michael Herzog}

Fachbereich Ingenieurwesen/Wirtschaftsingenieurwesen

Technische Hochschule Wildau [FH]

$\mathrm{T}+493375$ 508-332

michael.herzog@th-wildau.de 